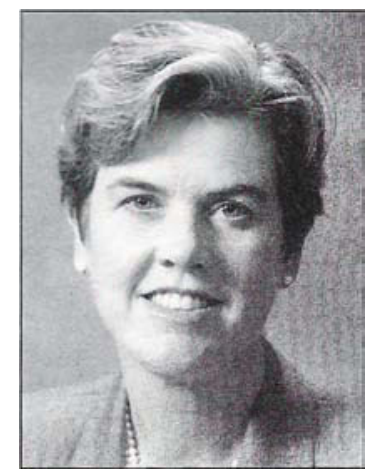

\title{
Agricultural, environmental issues need interdisciplinary approach
}

\author{
BARBARA SCHNEEMAN \\ Dean, College of Agricultural and Environmental Sciences \\ UC Davis
}

More than a century ago, the economy of the United States was based on a large farming population living on freely available farmland. Few farmers possessed the knowledge needed to change the face of agriculture from subsistence farming to a production system serving the economic and food and fiber needs of the nation. The government met this crisis by providing funds for a new type of institution, a "land grant" university that would conduct research, teaching, and outreach in agriculture and the mechanical arts and provide access for all to higher education. The land-grant university proved to be a powerful tool for advancing agriculture, through the extension of basic research developments in germplasm, cultural practices, and machinery, to the nation's farmers.

At the dawn of the 21st century, California - often a bellwether for the nation and the world - faces a crisis of equal magnitude. Unplanned growth and depletion of natural resources threaten the state's prosperous food production systems, its natural and biological resources, and the quality of life of all Californians. The University of California, like other institutions whose roots have been in agriculture, must respond to this crisis. It must restate its mission, emphasizing the total human food and fiber system from production to consumption. It must also recreate its scientific and public identities to survive in an era of rapid scientific change, vigorous policy debate and significant public disunity. We must link science, technology and productivity to environmental stewardship, land-use planning, sociopolitical concerns, and the preferences and practices of diverse consumer cultures.

To address the connections among such themes, it is imperative that universities move beyond organizational structures that segregate knowledge into discrete compartments. The University of California must be at the forefront of this new imperative, given its mandate to serve a large and multicultural population, a wide-ranging environment, and diverse and extensive food growing and processing industries.

We believe that a new paradigm is needed for dynamic research, education and outreach. Such a paradigm needs to move beyond outmoded and oversimplified binary oppositions (agriculture versus the environment, basic versus applied research) toward more integrative and systemic models emphasizing critical interdependencies. The need for such models becomes evident at a time when society is increasingly dependent on science and technology for food systems, communications and health care, yet increasingly suspicious of science and technology.

The critical need to foster interdisciplinary research and education has been a significant factor in planning for the future of the College of Agricultural and Environmental Sciences at UC Davis. In a yearlong process, 400 faculty and 95 specialists in 21 departments and divisions identified four major focal areas, and developed a strategic plan. The resulting, restructured college has been organized into four divisions, each with an associate dean. Our recently completed Academic Plan outlines the missions and objectives of each division. The four areas of divisional focus are:

- Environmental and Resource Sciences and Policy, which encompasses interactions among human, natural and agricultural resources. Programs in this area emphasize natural resource management, conservation, environmental stewardship, agricultural and managed ecosystems and public policy decision-making.

- Plant Sciences, which integrates molecular, cellular, and organismal plant biology to focus on understanding plant functions and interactions in both natural and agricultural systems. This integration will foster a productive agriculture within a sound ecological framework, optimizing sustainable production and minimizing environmental impact. - Animal Biology, which includes understanding and maintaining biological diversity, developing sustainable pest management strategies, and optimizing use of environmental resources in the management of wildlife, companion animals and the production of food.

- Human Health and Development, which addresses basic human needs (food, diet, clothing and shelter). This area links the postharvest processing of food and fiber with consumer health and well-being, emphasizing the continuum from production and processing to consumer use. Research focuses on physiological, psychological, social, material, and aesthetic dimensions of human health, comfort, safety, and quality of life.

In addition to these four primary areas of program emphasis, the College maintains a strong relationship with the Division of Biological Sciences, an intercollege division devoted to the basic biological sciences relevant to all program areas in the College.

Reductions in state support for the University have resulted in downsizing of the College and have compelled us to re-examine our priorities and the most effective mechanisms to accomplish our missions of teaching, research, service, and outreach. Our goal in restructuring the College is to engage students, faculty and traditional and new clientele in an educational process that connects science with societal issues.

We have identified associate deans in the four focal areas. They are charged with developing programmatic priorities and realigning resources to address them. Working together, these associate deans participate in our Dean's Council and are developing interdisciplinary interfaces across programmatic areas. The College is committed to continuing creative and timely planning to ensure that we maintain our responsibility to traditional clientele while addressing the broader issues that challenge effective management of human, natural and agricultural resources. 